\title{
MAGNETO-OPTICAL CHARACTERISTICS OF Tb-Fe-Co LAYERS COVERED WITH PERPENDICULAR MAGNETIC Co-Cr LAYERS
}

\author{
K.-B. SONG, S.-C. YU and M. NAOE \\ Department of Physical Electronics, Tokyo Institute of Technology, 2-12-1, O-okayama, Meguro-ku, Tokyo 152, Japan
}

\begin{abstract}
The bilayers composed of $\mathrm{Tb}-\mathrm{Fe}-\mathrm{Co}$ and $\mathrm{Co}-\mathrm{Cr}$ alloy layers have been prepared by using a facing targets sputtering apparatus. The specimen films revealed apparent magnetic coupling between ferrimagnetic $\mathrm{Tb}-\mathrm{Fe}-\mathrm{Co}$ and ferromagnetic $\mathrm{Co}-\mathrm{Cr}$ layers. The bilayers revealed Kerr rotation angle as large as $0.6 \mathrm{deg}$. at the wavelength of $633 \mathrm{~nm}$.
\end{abstract}

KEYWORDS: $\mathrm{Tb}-\mathrm{Fe}-\mathrm{Co}$ thin film, $\mathrm{Co}-\mathrm{Cr}$ thin film, facing targets sputtering, magneto-optical recording, perpendicular magnetic recording

\section{INTRODUCTION}

Nowadays, many researchers and engineers have been engaged with investigation of the interaction between magnetic multilayers. It is very important to clear these phenomena for developing and designing artificial materials with useful new characteristics. In this study, Tb-Fe$\mathrm{Co}$ and $\mathrm{Co}-\mathrm{Cr}$ bilayers have been prepared sequentially in order to investigate the interfacial effect between the layers. Ferrimagnetic amorphous $\mathrm{Tb}-\mathrm{Fe}-\mathrm{Co}$ and ferromagnetic crystalline $\mathrm{Co}-\mathrm{Cr}$ layers were famous about the usage of magneto-optical and perpendicular magnetic recording media with high perpendicular magnetic anisotropy energy [1]. Some interesting results would be introduced in this paper.

\section{EXPERIMENT}

The $\mathrm{Tb}-\mathrm{Fe}-\mathrm{Co} / \mathrm{Co}-\mathrm{Cr}$ bilayered films were sequentially deposited on plasma-free glass slide substrates by using a facing targets sputtering apparatus $[2,3]$. The compositions of the films were fixed about $\mathrm{Tb}_{20}\left(\mathrm{Fe}_{90} \mathrm{Co}_{10}\right)_{80}$ and $\mathrm{Co}_{82} \mathrm{Cr}_{18}$. Each layer was deposited at the argon pressure $P_{A r}$ of 0.5 mTorr and the deposition rate $R_{d}$ of $100 \mathrm{~nm} / \mathrm{min}$. The thickness $t_{M O}$ of magnetooptical $\mathrm{Tb}-\mathrm{Fe}$-Co layers was changed in the range between 5 to $300 \mathrm{~nm}$ and the thickness $t_{c_{0}-}$ $\mathrm{Cr}_{\mathrm{r}}$ of the perpendicular magnetic recording $\mathrm{Co}-\mathrm{Cr}$ layers was fixed at $100 \mathrm{~nm}$.

The Internal stress of specimen films was measured by bending beam method reviewed by Blackburn and Campbell [4]. The magnetic and magneto-optical characteristics have been investigated by using a vibrating sample magnetometer (VSM), a torque magnetometer and Kerr loop tracer. 


\section{RESULT AND DISCUSSION}

Figure 1 shows the compressive internal stress $\left|\sigma_{\mathrm{l}}\right|$ of $\mathrm{Tb}-\mathrm{Fe}-\mathrm{Co} / \mathrm{Co}-\mathrm{Cr}$ bilayers dependent on $t_{\mathrm{MO}}$ with $\mathrm{t}_{\mathrm{Co-Cr}}$ of $100 \mathrm{~nm}$. The compressive stress reduced with increasing $t_{M O}$.

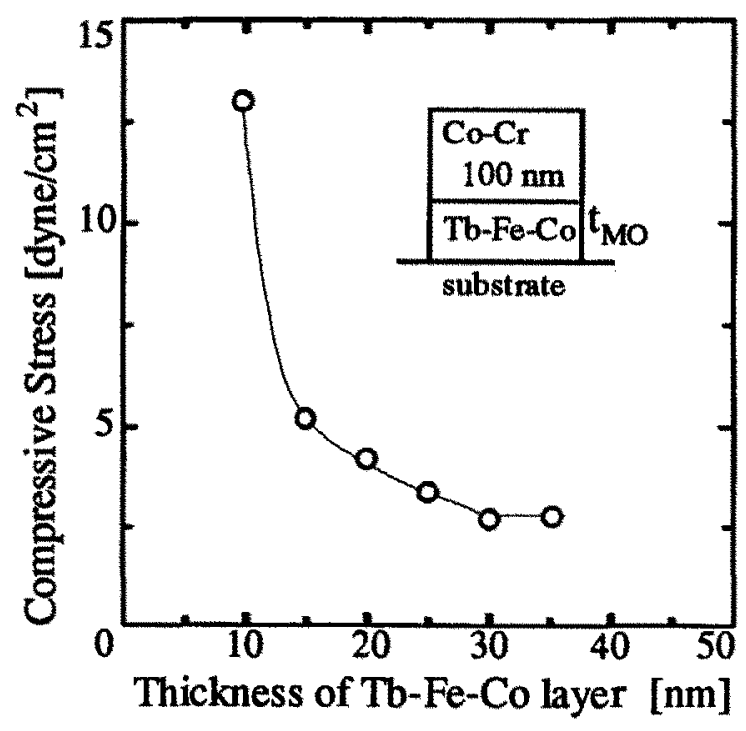

Fig. 1. compressive internal stress $\left|\sigma_{\mathrm{I}}\right|$ of Tb$\mathrm{Fe}-\mathrm{Co} / \mathrm{Co}-\mathrm{Cr}$ bilayers dependent on $\mathrm{t}_{\mathrm{MO}}$

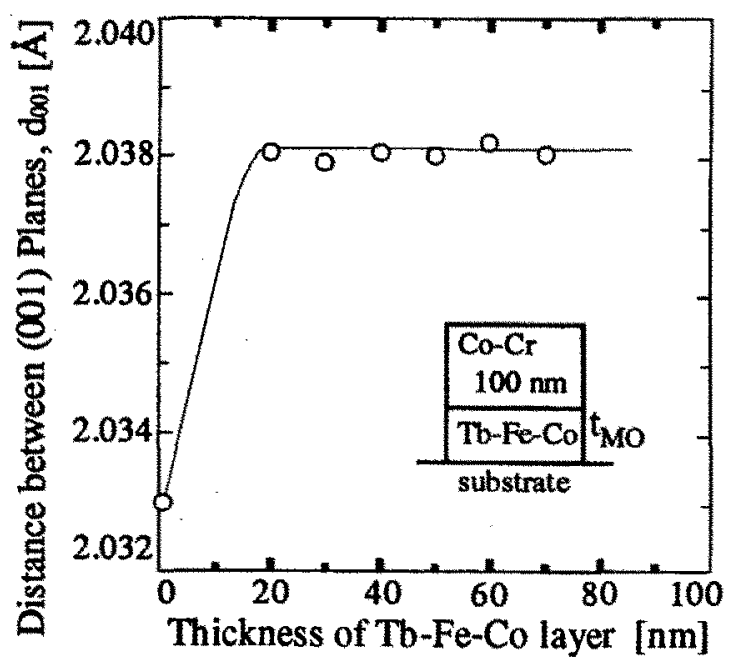

Fig. 2. Distance of (001) plane $d_{001}$ of crystalline $\mathrm{Co}-\mathrm{Cr}$ layer dependent on $\mathrm{t}_{\mathrm{MO}}$
The $\mathrm{x}$-ray diffraction pattern of specimen bilayers revealed a (001) peak of hexagonal Co$\mathrm{Cr}$ layers. Figure 2 and 3 show the distance of (001) plane $d_{001}$ and the crystal size $\langle D\rangle_{001}$ of Co-Cr crystalline dependent on $t_{M O}$. The $d_{001}$ of bilayers increased to the value of $2.038 \AA$ from $2.033 \AA$ of $\mathrm{Co}-\mathrm{Cr}$ single layer. The $\langle\mathrm{D}\rangle_{001}$ decreased from $330 \AA$ to $220 \AA$. The crystal size of $\mathrm{Co}-\mathrm{Cr}$ single layer was restricted by bilayer. And the degree of crystal orientation $\Delta \theta_{50}$, which was estimated by the full width of half maximum of the (001) rocking curve, increased from $8 \mathrm{deg}$. to 10 deg., as illustrated in Fig. 4.

Figure 5 shows the magnetization curves of (a) Tb-Fe-Co single layer with $t_{M O}$ of $30 \mathrm{~nm}$, (b) Co-Cr single layer with $t_{\mathrm{Ca}-\mathrm{Cr}}$ of $100 \mathrm{~nm}$ and (c) $\mathrm{Tb}-\mathrm{Fe}-\mathrm{Co} / \mathrm{Co}-\mathrm{Cr}$ bilayer with $t_{\mathrm{MO}}$ and $\mathrm{t}_{\mathrm{Co}-\mathrm{Cr}}$ of 30 and $100 \mathrm{~nm}$, respectively, where $(\perp)$ and solid line represent the hysteresis loops observed for fields applied in the direction perpendicular to the layer plane, on the other hand ( /I) and dashed line represent the in-plane loop.

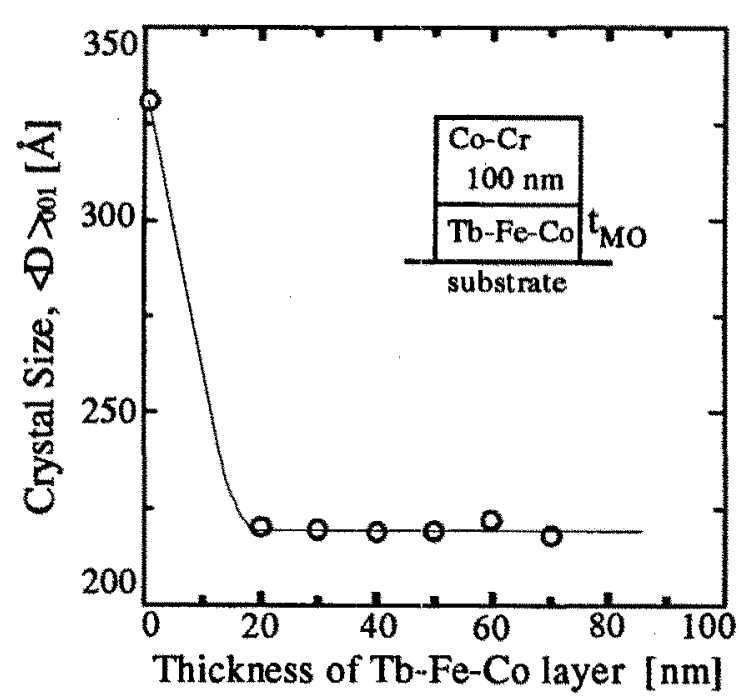

Fig. 3. Crystal size $\langle\mathrm{D}\rangle_{001}$ of crystalline Co$\mathrm{Cr}$ layer dependent on $\mathrm{t}_{\mathrm{MO}}$ 


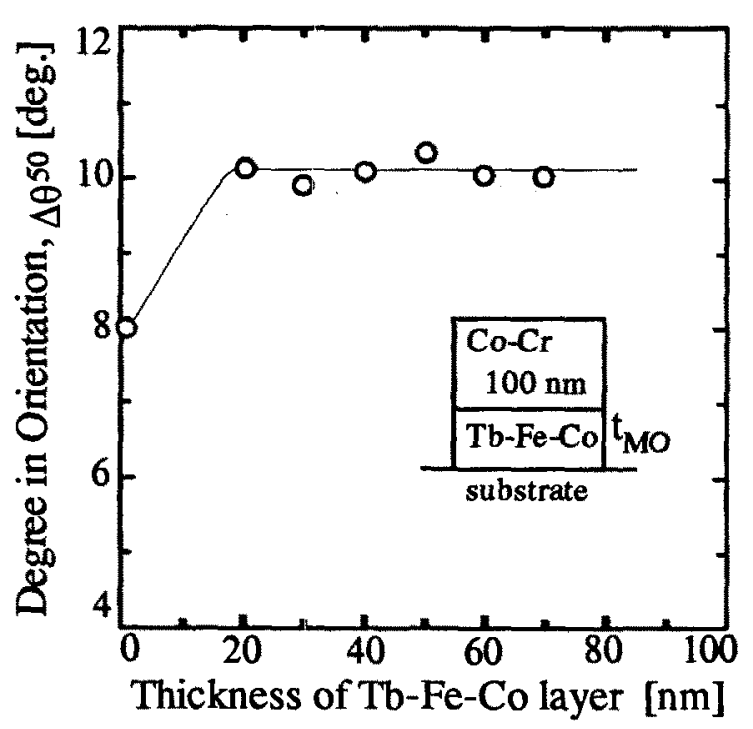

Fig. 4. Degree of crystal orientation $\Delta \theta_{50}$ of $\mathrm{Co}-\mathrm{Cr}$ layer dependent on $\mathrm{t}_{\mathrm{MO}}$

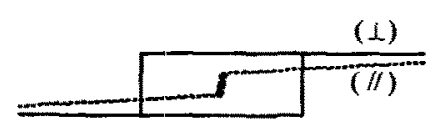

(a) Tb-Fe-Co $(30 \mathrm{~nm})$

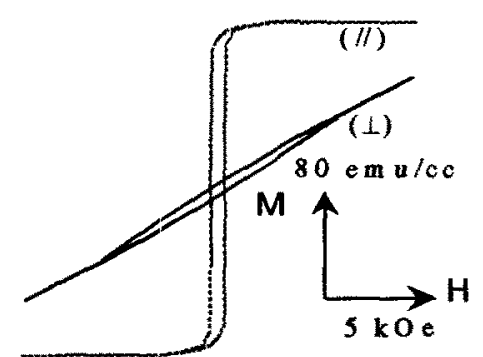

(b) $\mathrm{Co}-\mathrm{Cr}(100 \mathrm{~nm})$

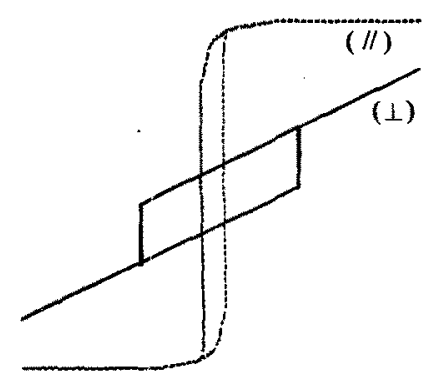

(c) $\mathrm{Tb}-\mathrm{Fe}-\mathrm{Co} / \mathrm{Co}-\mathrm{Cr}$

Fig. 5. M-H curves of (a) $\mathrm{Tb}-\mathrm{Fe}-\mathrm{Co}$ (b) $\mathrm{Co}-\mathrm{Cr}$ single layers and (c) $\mathrm{Tb}-\mathrm{Fe}-\mathrm{Co} / \mathrm{Co}-\mathrm{Cr}$ bilayer
The specimen bilayers showed a sharp rectangular perpendicular hysteresis loop with the coercivity $\mathrm{H}_{\mathrm{c}}$ almost same as that of the $\mathrm{Tb}$ Fe-Co single layer, where the side of the loop was slightly sloped, but the in-plane hysteresis loop exhibited larger $\mathrm{H}_{c}$ than those of $\mathrm{Tb}-\mathrm{Fe}-\mathrm{Co}$ and $\mathrm{Co}-\mathrm{Cr}$ layers.

Figure 6 shows the $t_{M o}$ dependence of $\theta_{K}$ for $\mathrm{Tb}-\mathrm{Fe}-\mathrm{Co} / \mathrm{Co}-\mathrm{Cr}$ and the Kerr hysteresis loops observed from the substrate side at the wavelength $\lambda$ of $633 \mathrm{~nm}$. $\theta_{K}$ of these bilayer took maximum of $0.6 \mathrm{deg}$. at $t_{\text {Mo }}$ of about $30 \mathrm{~nm}$. The Kerr hysteresis loops of bilayers with semihard magnetic $\mathrm{Co}-\mathrm{Cr}$ overlayers with $\mathrm{t}_{\mathrm{MO}}$ more than $25 \mathrm{~nm}$ revealed rectangular loop shape. The loop shape became similar to that of $\mathrm{Co}-\mathrm{Cr}$ layers with decrease of $t_{M O}$.

Figure 7 shows the reflectivity $\mathrm{R}$ of $\mathrm{Tb}-\mathrm{Fe}-$ $\mathrm{Co} / \mathrm{Co}-\mathrm{Cr}$ bilayers observed from the substrate side at $\lambda$ of $633 \mathrm{~nm}$. Higher $\mathrm{R}$ of $\mathrm{Co}-\mathrm{Cr}$ single layer decreased with increasing $t_{M O}$ from 60 to

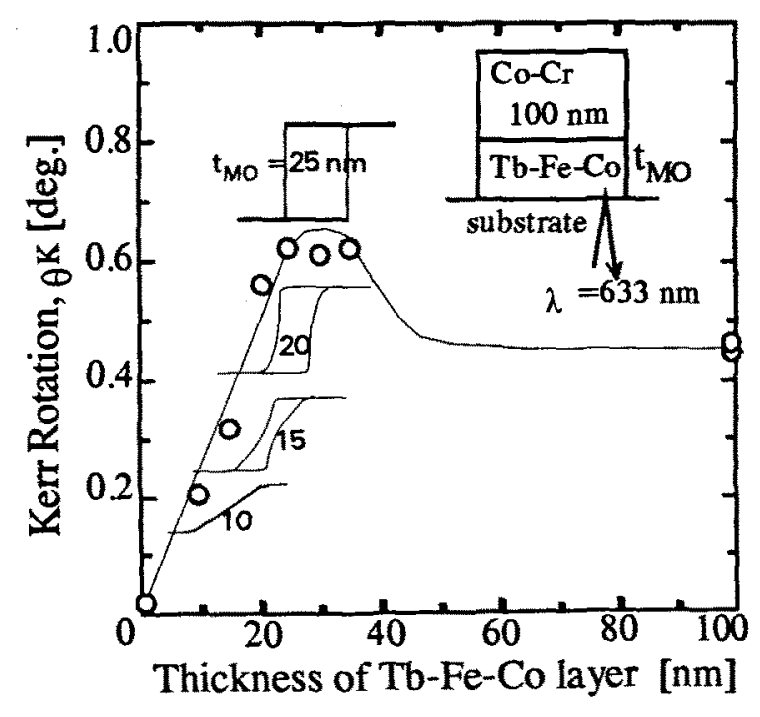

Fig. 6. $\mathrm{t}_{\mathrm{MO}}$ dependence of Kerr rotation $\theta_{\mathrm{K}}$ of $\mathrm{Tb}-\mathrm{Fe}-\mathrm{Co} / \mathrm{Co}-\mathrm{Cr}$ bilayers 


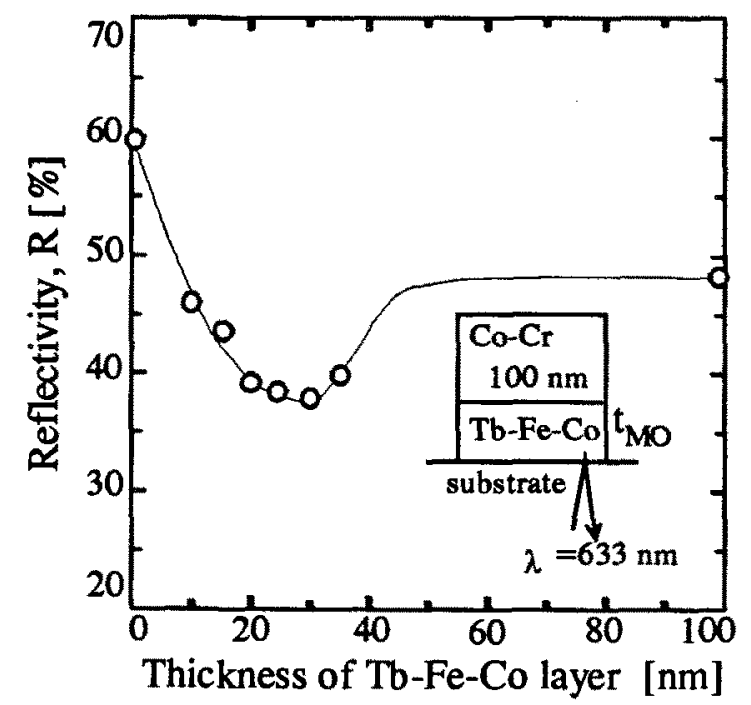

Fig. 7. $t_{M O}$ dependence of reflectivity $R$ of $\mathrm{Tb}-\mathrm{Fe}-\mathrm{Co} / \mathrm{Co}-\mathrm{Cr}$ bilayers

the minimum value of $37 \%$ at $\mathrm{t}_{\mathrm{MO}}$ of about 30 $\mathrm{nm}$, and it increased with increasing $t_{\mathrm{MO}}$ and converged about $49 \%$, which is the $\mathrm{R}$ of single Tb-Fe-Co layer.

\section{CONCLUSIONS}

$\mathrm{Tb}-\mathrm{Fe}-\mathrm{Co} / \mathrm{Co}-\mathrm{Cr}$ bilayers composed of amorphous $\mathrm{Tb}-\mathrm{Fe}-\mathrm{Co}$ and crystalline $\mathrm{Co}-\mathrm{Cr}$ layers have been prepared by using a facing targets sputtering apparatus. Results are as follows;

(1)The specimen bilayers shows large Kerr rotation angle of $0.6 \mathrm{deg}$. at $\mathrm{t}_{\mathrm{MO}}$ of about $30 \mathrm{~nm}$.

(2) The bilayers revealed poor degree of crystal orientation $\Delta \theta_{50}$ of about $10 \mathrm{deg}$.

(3) The normal magnetization curve seems a simple superposition of each $\mathrm{M}-\mathrm{H}$ curves, but the change of shape and $\mathrm{H}_{\mathrm{c}}$ of the in-plane $\mathrm{M}-\mathrm{H}$ curve implies a kind of magnetic interaction between $\mathrm{Tb}-\mathrm{Fe}-\mathrm{Co}$ and $\mathrm{Co}-\mathrm{Cr}$ layers.

\section{REFERENCE}

[1] S. Iwasaki, K. Ouchi, and N. Honda, IEEE Trans. Magn., MAG-16, (1980), 1111

[2] M. Naoe, S. I. Yamanaka, and Y. Hoshi, IEEE Trans. Magn., MAG-16, (1980), 646

[3] Y. Niimura, S. Nakagawa, and M. Naoe, Material Science \& Engineering, 98, (1988), 53

[4] H. Blackburn and D. S. Campbell, Phil. Magn., V.8, (1963), 923 